3. Lu Yuytszyun (2013). Features of the foreign period of creativity S. Rachmaninov. Music art and culture, 18, 404-413. Odessa: Astroprint [in Russian].

4. Protopopov V. Variational processes in musical form. Moscow: Muzyika [in Russian].

Стаття надійшла до редакиї 22.11.2017

УДК 78.03+78.083.23

DOI 10.31723/2524-0447-2018-26-200-213

Лу До

https://orcid.org/0000-0002-9661-3308

соискатель кафедры теории музыки и композиции

Одесской национальной музыкальной академии

имени А. В. Неждановой

mzlvduo@qq.com

\title{
ПЕРВОЕ ИНТЕРМЕЦЦО В ИСТОРИИ МУЗЫКИ: Р. ШУМАН, ОР. 4, № 1
}

Цель статьи - выявить первый образеи жанра интермецио как самостоятельного произведения в творчестве Роберта Шумана. Рассмотреть, систематизировать и проанализировать особенности взаимодействия содержательных компонентов в Интермецио ор. 4, № 1 композитора и сделать выводы о своеобразии их соотношений в произведении. На материале анализа тематизма, тонального плана, формы первого в истории музыки интермецио у Шумана выявить его особенности. Возникла также необходимость показать перспективность исполнения интермецио ор. 4, № 1, т.к. в учебной и концертной практике в Украине исполняются выборочно лишь отдельные произведения из этого цикла, то же происходит и в Китае. Методология статьи применены методы историко-культурологического, теоретического и жанрово-стилевого анализа, что позволило осветить своеобразие и неповторимость жанрового мышления Роберта Шумана относительно появления жканра интермецио в его творческой индивидуальности и в контексте дальнейшего исследования развития жанровых особенностей интермецио. Научная новизна статьи заключается в том, что раскрывается в полной мере отношение Роберта Шумана к открытию самостоятельного жанра - интермецио, наполненного композитором принципиальной новизной, происходящей из его понимания такого жанра, $и$ воспроизводящего его романтическим стилем того времени и обновленной фортепианной техникой. Исходя из жанрового анализа интермецио выведена и подтверждена собирательная формулировка этого понятия 
на этапе его открытия и романтизма. Выводы. Жанровые открытия Роберта Шумана и особенности его мышления направлены далеко в будущее. Это относится и к жанру интермеццо, основоположником которого является Роберт Шуман, впервые создавший произведение с таким названием. У него же интермецио становится как самостоятельным произведением, так и частью иикла (фортепианного концерта). В дальнейшем жанр интермеццо стал чрезвычайно популярным как самостоятельная пьеса и как часть циклического произведения: в сонатах, концертах, циклах различных пьес, куда вторгается и интермеццо. У Шумана жанр интермецио приобретает яркое внутреннее содержание, насыщенное серьезным драматургическим развитием, столь разнообразно используемое композитором. Шуман как бы зачал этот жанр и, вместе с тем, будто подвел итог развитию жанра в ранний период истории романтизма, показал его индивидуальные особенности и сосредоточенность на внутренней специфике содержательности и пианизма. Шуман совмещает классическое прошлое и современное, вобрав основы мышления романтизма и во многом предвосхитив будущее музыкального языка ХХ столетия. Интермецио Шумана перспективны для исполнения как в Украине, так и в Китае.

Ключевые слова: жканр, романтизм, Роберт Шуман, первое интермецио, драматургия, лейткомплекс, лейтритмическая единица, лейтинтонация.

Lu Do, degree-seeking of The Department of music theory and composition of Odessa National A. V. Nezhdanova Academy of Music

The First Intermezzo in the music history: R. Schumann, op. 4, № 1

The purpose of the article is to reveal the first sample of an intermezzo genre as an independent work in the creative works of Robert Schumann. To consider, systematize and analyze the features of the interaction of content components in Intermezzo op. 4 № 1 of the composer and to draw conclusions about the unique nature of their ratio in this work. On the material of the analysis of thematism, tonal plan, the form of the first ever in the history of music intermezzo by Schumann to suggest to reveal its features. There was also a need to show the prospects for the performance of intermezzo op. 4№ 1, as in the educational and concert practice in our country only some works from this cycle are performed selectively, as it is in China as well. Methodology of the article - methods of historical and cultural, theoretical and genre-style analysis have been applied, which made it possible to elucidate the originality and uniqueness of the genre thinking of Robert Schumann regarding the appearance of an intermezzo genre in his creative individuality and in the context of a further research of the development of the genre features of intermezzo. The scientific novelty of the article is that Robert Schumann's attitude towards the discovery of an independent genre-intermezzo is fully revealed. The composer filled it with principal novelty originating from his understanding of this genre and reproducing it with the ro- 
mantic style of that time and with updated piano technique. On the basis of the genre analysis of intermezzo, the collective wording of this concept at the stage of its discovery and romanticism was deduced and confirmed. Conclusions. The genre discoveries of Robert Schumann and the features of his thinking are directed far into the future. This is also applied to a genre of intermezzo, whose founder is Robert Schumann, first creating a work under this name. His intermezzo becomes both $n$ independent work and a part of the cycle (piano concerto). In the future, an intermezzo genre became extremely popular, both as an independent play and as a part of the cyclical work: in sonatas, concerts, cycles of various plays, where intermezzo also invades. In the works of Schuman, an Intermezzo genre acquires a vivid inner content, saturated with serious dramatic development, so diversely used by the composer. Schumann, as if conceived this genre and, at the same time, as if summed up the development of this genre in the early period of the history of Romanticism, showed its individual characteristics and focus on the internal specifics of content and pianism. Schumann combines the classical past and the modern future, taking up the basics of the thinking of Romanticism and in many ways anticipated the future of the musical language of the XX century. Intermezzos of Schumann are promising for performance both in our country and in China.

Keywords: genre, Romanticism, Robert Shumann, first intermezzo, dramaturgy, leit-complex, leit-rhythmic unit, leit-intonation.

Лу До, здобувач ступеня кандидата мистецтвознавства кафедри теорії музики та композиції Одеської національної музичної академії імені А. В Нежданової

\section{Перше інтермеццо в історії музики: Р. Шуман, ор. 4, № 1}

Мета статі - виявити перший зразок жанру інтермецо як самостійного твору в творчості Роберта Шумана. Розглянути, систематизувати і проаналізувати особливості взаємодії змістовних компонентів в Інтермеццо ор. 4, № 1 композитора і зробити висновки про своєрідність їх взаємодій в цьому творі. На матеріалі аналізу тематизму, тонального плану, форми першого в історії музики інтермеццо у Шумана запропонувати та виявити його особливості. Виникла також необхідність показати перспективність виконання Інтермецио ор. 4, № 1, бо в учбовій та концертній практиці в Україні виконуються виключно лише окремі твори з цього циклу, така жк картина і в Китаї. Методологія статmi - використані методи історико-культурологічного, теоретичного і жанрово-стильового аналізу, що дозволяє висвітити своєрідність та неповторність жанрового мислення Роберта Шумана відносно появи жанру інтермеццо в його творчій індивідуальності і в контексті подальшого дослідження розвитку жанрових особливостей інтермецио. Наукова новизна статті в тому, що розкривається в повній мірі відношення Роберта Шумана до відкриття самостійного жанру - інтермеццо, наповненого композитором принциповою новизною, що походить із його ро- 
зуміння такого жанру, та відтвореного його романтичним стилем того часу і оновленою фортепіанною технікою. Виходячи з жанрового аналізу інтермецио, виведене та підтверджене збиральне формулювання цього поняття на етапі його відкриття і романтизму. Висновки. Жанрові відкриття Роберта Шумана та особливості його мислення спрямовані далеко в майбутнє. Це стосується і жанру інтермецио, основоположником якого є Роберт Шуман, вперше створив твір з такою назвою. У нього ж інтермецио стає як самостійним твором, так $і$ частиною ииклу (фортепіанного концерту). Надалі жанр інтермецио став надзвичайно популярним як самостійна п'єса і як частина циклічного твору: в сонатах, концертах, циклах різних п'єс, куди вторгається і інтермеццо. У Шумана жсанр інтермецио набуває яскравого внутрішнього змісту, насиченого серйозним драматургічним розвитком, так різноманітно використаного композитором. Шуман ніби зачав цей жканр $i$, разом з тим, ніби підвів підсумок розвитку жанру в ранній період історії романтизму, показавщи його індивідуальні особливості та зосередженість на внутрішній специфіці змістовності і піанізму. Шуман поєднує класичне минуле і сучасне, вбираючи основи мислення романтизму $i$ багато в чому передбачаючи майбутне музичної мови ХХ століття. Ітермеццо Шумана перспективне для виконання піаністами як в Україні, так и в Китаї.

Ключові слова: жанр, романтизм, Роберт Шуман, перше інтермецио, драматургія, лейткомплекс, лейтритмічна одиниия, лейтінтонація.

Актуальность темы исследования. Творчество Роберта Шумана одно из наиболее интересных и значительных явлений в немецкой музыкальной культуре XIX столетия. Наряду с творчеством таких гениев, как Г. Гейне, молодой Р. Вагнер, Ф. Мендельсон, произведения Р. Шумана отражали художественный подъем и социальные сдвиги, процесс становления профессиональной музыкальной культуры в Германии; появление многих новых жанров и их сочетание в циклы.

Роберт Шуман представитель раннего романтизма: композитор, публицист, мыслитель, общественный деятель. Репутация Шумана в кругу музыкантов-современников была весьма высока.

Своеобразная судьба творческого наследия Роберта Шумана. Еще при жизни (1810-1856) композитора общественное мнение было склонно оценивать его как самого оригинального музыканта и композитора послебетховенской эпохи, но произведения последнего периода длительное время оставались не оцененными (хотя огромную роль в пропаганде его творений сыграла Клара Вик).

Иное отношение к ранним произведениям Роберта Шумана, к его жанровым поискам, в том числе к жанру интермеццо. Шуман принадлежит к числу художников, у которых замысел и воплощение в 
музыкальном произведении достигли высокой степени единства и целостности.

Остановимся на интермеццо как самостоятельном жанре в творчестве Шумана, придуманном и введенном им в композиторскую практику. Шесть пьес под общим названием Интермеццо (Intermezzi op. 4,1832 ) были посвящены И. Калливоде - чешскому композитору, скрипачу и дирижеру. Это одно из талантливейших сочинений молодого Шумана (которое даже не упоминается в перечне его произведений).

По сравнению с «Бабочками», завершенными в предшествуюшем году (1831), тематический материал интермеццо стал более своеобразным, характерным; в нем отсутствует музыка, не обладающая яркой образностью.

«Интермеццо» ор. 4 - одно из первых произведений, где композитор достаточно отчетливо применяет композиторскую технику, использованную позже в «Давидсбюндлерах». Если обратить внимание на самостоятельность тематизма пьес «Интермеццо», то объединяющая функция интонационного лейткомплекса становится здесь особенно существенной.

Цель статьи - выявить первый образец жанра интермеццо как самостоятельного произведения в творчестве Роберта Шумана. Рассмотреть, систематизировать и проанализировать особенности взаимодействия содержательных компонентов в Интермеццо ор. 4, № 1 композитора и сделать выводы о своеобразии их соотношений в произведении. На материале анализа тематизма, тонального плана, формы первого в истории музыки интермеццо у Шумана предложить выявить его особенности.

Возникла также необходимость показать перспективность исполнения интермеццо ор. 4, № 1, так как в учебной и концертной практике в Украине исполняются выборочно лишь отдельные произведения из этого цикла, то же происходит и в Китае.

Изложение основного материала. В эпоху романтизма появилось много новых жанров, а «старые», исторически сложившиеся, обновлялись, в них вносилось иногда принципиально новое содержание. Появился и новый фортепианный жанр в творчестве Роберта Шумана - интермеццо.

Рассмотрим первое в истории музыки фортепианное интермеццо Роберта Шумана с точки зрения его драматургии и формы ее воплощения. 
Возможно, к «Интермеццо» Шумана наиболее подходят слова Г. Головинского: «Метод Шумана... точнее определить как «доращивание» исходной лейтинтонации до темы, каждый раз иной, но не как вариации на тему» $[1,50]$. Впрочем, на наш взгляд, удобнее употреблять термин «наращивание», если речь идет о дополнении к начальному построению темы, и «доращивание», если трансформируется завершение темы.

Первое интермеццо открывает сюитный цикл ор. 4. Естественно, в нем заключается основа для всего цикла, а важную роль выполняют особенности содержания и строения самого интермеццо.

Важнейшее значение трех вступительных тактов, содержащих лейтинтонацию всего цикла - нисходящую малую секунду, а также лейтритмическую единицу (синкопу шестнадцатая - восьмая). В целом они составляют лейткомплекс.

Главную тему пьесы этого интермеццо можно считать родоначальницей целого круга шумановских образов, выражающих страстную, но притом и несколько сумрачную энергию. Тема, предельно сжатая и насыщенная, сразу же захватывает внимание острым интонационным оборотом (вариант лейтмотива опевания) - малой ноны, подчеркнутой динамическим акцентом. При такой остроте и краткости темы вполне естественным становится ее полифоническое развитие в виде типично шумановских, четко набегающих друг на друга, стреттных имитаций: в приму, секунду, кварту; с постоянным временным расстоянием в один такт.

Типичное «баховское» опевание Шуман иногда преобразует в восходящую малую нону - нисходящую малую секунду (как в принципе и восходящую секунду), то есть секундовое движение преобразуется, расширяясь до ноны. Тем не менее, опевание становится одним из основных лейтмотивов всего цикла интермеццо.

Следует также обратить внимание на композиторскую ремарку к интермеццо: «Allegro quasi maestoso», что может быть переведено следующим образом: «Быстро и как бы торжественно». Это весьма специфическая ремарка, достаточно редко употребляемая композиторами.

Шуман интересно решает сложную трехчастную форму, в которой написано интермеццо. Первая часть интермеццо затем повторяется - точная реприза. Лишь второй шеститакт главной темы (тт. 9-14) изымается из репризы и переносится в коду, превращая ее как бы в продолжение репризного раздела. 
Данная часть интермеццо создана в не нормативной трехчастной репризной форме, с развитой разработкой и динамической репризой.

Вступление выполняет лейтмотивную, лейтритмическую, формообразующую, содержательную роль во всем произведении. Вступительная партия (ВП) очень яркая - это два звена секвенции, состоящие в свою очередь из двух секундовых нисходяще-восходящих реплик, характерных начальной неустойчивостью с дальнейшим разрешением. В первом звене верхний голос аккордов: $\mathrm{d}$ - cis, a - gis; нижний голос октав: gis - a, dis - e. Начинается тема вступления c D6/5, разрешаемого в тонику; затем DD6/5 в доминанту. Все неустойчиво-устойчиво и звучит FF. Второе звено секвенции просто повторяет первое, утверждая его.

После трехтактового вступления (FF) звучит главная тема, созданная в форме не нормативного периода, достаточно показательного для Шумана (что говорит о скрытой программности произведения). Состоит она из двух редко встречающихся столь контрастных разделов: а (5 и 1/4 такта) + в (6 и 3/4 такта), также вбирающих интонации вступительной партии (в ней содержится также лейтинтонация и лейтгармония всего цикла интермеццо).

Первое предложение очень яркое - это четырехголосный канон, где каждое вступление темы начинаются со скачка ноны с дальнейшим ее поступательным поступенным заполнением, что отмечено f и sf. Вступление тем в каноне лестничное: идет снизу - вверх, от звуков cis - cis - cis - fis, c тональным содержанием fis-moll - A-dur; пропоста длится один такт.

Второе предложение (от FF) не менее яркое, но совершенно иное. Построено на восходящем гаммообразном движении по звукам гаммы A-dur, направленном каждый раз от р к FF и охватывающем широкий диапазон клавиатуры фортепиано (от контроктавы до третьей). После канона первого предложения параллельное октавно-аккордовое движение звучит особенно ярко и контрастно.

Схема строения главной темы интермеццо № 1:

\begin{tabular}{|c|c|}
\hline A & В \\
\hline 5 и $1 / 4$ такта & 6 и 3/4 такта \\
\hline fis-moll - A-dur - совершенный каданс & A-dur - совершенный каданс \\
\hline Фактура имитационная - канон & Октавное движение \\
\hline
\end{tabular}

Таким образом, необычность тематического материала и его сопряжения состоит в том, что после совершенного каданса в начале 
шестого такта, композитор предлагает принципиально иной содержательный и фактурный материал: восходящее аккордовое движение с повторами в более высоких октавах. Первая часть дважды повторяется знаком повтора, как в классических частях разделов сонат, менуэтов, скерцо и т. п. (У Шумана в интермеццо часто встречаются повторы различных отдельных частей-периодов).

Композиционное ядро «Интермеццо» в меньшей степени, чем в «Давидсбюндлерах», растворено в тематизме пьес. Полнее сохраняя первоначальный облик, оно достаточно самостоятельное и автономное, появляется как лейтмотив, «как своего рода навязчивая идея, не оставляющая «героя» произведения на всем протяжении цикла» $[5,43]$.

Чаще всего данный лейтмотив (элемент темы) возникает в моменты драматического напряжения, часто завершая предкульминационные нарастания. Такая выразительная функция лейтосновы первого интермеццо определена уже в начале произведения.

Середина интермеццо также интересная: при резкой смене динамики на p, это разработка (fis-moll) трихорда из главной темы на фоне спокойно движущегося баса (4 такта), затем вычлененного из нее же нисходящего движения (с двойным ритмическим уменьшением до шестнадцатой с двумя точками - тридцать вторая) на фоне нового яркого мотива «зова» с квартовым скачком (1 такт); который переходит в «зов» начального мотива главной партии, то есть потом построена на самой главной теме (опять имитационное изложение тт. 21-25 - с начальных септимы, ноны, септимы); и возвращение, как обрамление темы вступления, которой композитор придает большое значение (в новом ритмическом обличии и комплементарной фактуре - тт. 25-28).

Вновь имитационно звучит тема главной партии на фоне продолженных звуков в басу. И тут в мелодии появляется новый вариант интонаций из вступительной партии: медленно изложенные хроматические секунды в трех секвенциях (тт. 28-33). Следующий раздел связан с одновременным развитием - контрапунктом - тем главной и вступительной партий, звучащих на динамике ff (тт. 33-34).

Возвращение незначительно измененного вступления в основной тональности (тт. 33-35) начинает репризу первой части интермеццо. После чего точно звучит первое предложение главной партии (таким образом, она сокращена за счет второго предложения).

Средняя часть пьесы (Alternativo - именно такое название композитор постоянно использует для средних частей интермеццо) 
несколько удивляет парадоксальным контрастом: рядом с сосредоточенной мужественностью - легковесное пританцовывающее движение, и затем вдруг, как бы в новой «маске», весьма весело и непринужденно звучит вариант главной темы в A-duг (параллельная тональность).

Начинается Alternativo двумя тактами вступления с «новыми» квартовыми зовами, которые дают интонационный импульс к содержанию средней части.

И лишь затем звучит она сама - Piu vivo (pp) - жанрово близкая скерцо. Все построено на квартовых зовах в двух голосах и опеваниях в нижнем - в D-dur (тональность VI ступени). Здесь происходит удивительный синтез темы середины с темой главной партии первой части, вернее звучит их постоянное чередование $(\mathrm{c}+\mathrm{a} 1)$.

Середина интермеццо (Alternativo) вновь построена в сложной трехчастной репризной форме с разработкой внутри. Композитор не может расстаться с образом главной партии - несущим драматическое, напряженное начало в пьесе и построенным на секундах вступительной, которая активно появляется в разработке средней части.

Схема строения средней части интермеццо № 1:

\begin{tabular}{|c|c|c|c|c|}
\hline ВП & $\mathrm{C}$ & $\mathrm{C} 1$ & Разработка & $\mathrm{C} 1$ \\
\hline 2 & 8 & 9 & 7 & 9 \\
\hline & $\mathrm{c}+\mathrm{a} 1$ & $\mathrm{c}+\mathrm{a} 2$ & ГП/ВП ВП & $\mathrm{C}+\mathrm{a} 2$ \\
\hline & $4+4$ & $4+5$ & $3+2+2$ & $4+5$ \\
\hline & $\mathrm{D}-$ dur & & FF pp & \\
\hline
\end{tabular}

Реприза интермеццо возвращает основные образы - вступительной и главной партий в полном объеме первого периода. Так завершилось первое в истории музыки интермеццо - ор. 4, № 1 Роберта Шумана, наполненное драматическим напряжением и скерцозностью.

«Одно шутовское интермеццо преследует меня день и ночь», - записывает Шуман в дневнике 22 июля 1832 года. И тут же продолжает: «шутовское интермеццо - в сущности, крик из глубины души» (выделено нами. - Л. Д.; цит. по [2, 351]). Данная запись, скорее всего, относится к первой пьесе, где отчетливо выражен столь волновавший Шумана «контрапункт» жизни, как «крик из глубины души»: сочетание пылкого эмоционального стремления с озорной насмешкой, шуткой.

Известно, что когда в основе шумановских мелодий лежит какойлибо «островыразительный» оборот (в данном случае во вступитель- 
ной и в главной партии), дальнейшее течение мелодической линии нередко основано на многократном повторении, перемещении или варьировании исходной мысли, что углубляет ее восприятие. Добавляется в пьесу также рондальный компонент, который выполняется, как здесь, постоянно повторяющейся вступительной партией и начальным мотивом главной.

Вспомним, что так развиваются, например, тема романса из «Венского карнавала»; тема пьесы «Почему?» из «Фантастических пьес», ор. 12; вторая тема из третьей части «Фантазии» Роберта Шумана. Такого же типа тема из «Интермеццо» ор. 4, № 1, где многократное повторение начального выразительного оборота оформлены в виде имитационных построений, что типично для творческого мышления Шумана [2, 428], затем проведений в различных тональностях, вычленение разных элементов из темы, которая оказывается основным носителем важнейшего для произведения образа.

Как и во всех ранних циклах, темы интермеццо чрезвычайно лаконичны, они чаще сопоставляются между собой, как бы «нанизываются» одна на другую, чем внутренне развиваются.

Данное интермеццо оказывается одним из первых жанровых сочинений Роберта Шумана, где композитор достаточно отчетливо использует композиционную технику, примененную в «Давидсбюндлерах». И если учесть большую самостоятельность ранних пьес интермеццо в цикле ор. 4, то объединяющая функция интонационного лейткомплекса становится особенно существенной. Намечаются и другие черты, свойственные стилю фортепианных циклов Шумана: скрытая сюжетная программность, о которой можно судить не только по характеру музыки, ее жанровости, но и по высказываниям композитора; своеобразное обрамление, стремление к следованию частей без перерыва (attacca).

Фактура произведений Шумана, в том числе и интермеццо, весьма специфична и индивидуальна. Цикл раннего периода творчества Роберта Шумана - «Интермеццо» ор. 4 - буквально пронизан полифонической фактурой, имитациями, канонами и т. п., выполняющими важную роль в произведениях (экспозиционную, срединную, развивающую, репризную).

Шуман считал, что в теории он школьник, хотя в композиторской практике уже обладал некоторым солидным багажом: Вариации на тему Abegg, «Бабочки», первая тетрадь этюдов по каприсам Н. Паганини, Интермеццо, «Экспромт» на тему Клары Вик, Симфония g-moll, 
три вариационных цикла - на тему из аллегретто Седьмой симфонии Л. ван Бетховена, на тему Р. Шуберта и ноктюрна Ф. Шопена.

Позже Роберт Шуман весьма придирчиво критиковал свои ранние произведения и многие из них «доделывал». Тем не менее, «Бабочки», «Интермеццо» ор. 4, «Экспромт» ор. 5 он не трогал - это уже, несомненно, «начало настоящего Шумана, работы блестящего и оригинальнейшего мастера» [2, 138]. Мы бы сказали точнее: это уже произведения истинного Шумана, высокопрофессионального композитора.

Итак, в 30-е годы XIX века композиторский гений Шумана раскрывается во всей полноте. Появляются его лучшие фортепианные произведения: «Бабочки», «Интермеццо», «Карнавал», сонаты, «Симфонические этюды», «Фантазия», «Крейслериана» и др.

Обратимся к принципам исполнения «Интермеццо». Исполнитель, стремящийся к целостной интерпретации всего цикла, должен осознать интонационные связи-арки. Шуман в «Интермеццо» несколько облегчает эту задачу исполнителю при помощи различных обозначений: это короткие лиги, sf, знаки резкого акцента и другие. Так он тщательно выделяет начало лейткомплекса. Более того, иногда интонационное зерно цикла помещается, например, на гребень кульминационной динамической волны, что делает просто невозможным не подчеркнуть его.

И все же исполнителю-интерпретатору остается немало аналитической работы, ибо ткань сочинения полифоническая, густая, многозвучная, а проявления лейтосновы не всегда элементарны. Например, в т. 24-27 первого интермеццо вариант тематического элемента (вступления, которое вообще недооценивается в данной пьесе) обычно не дослушивается и «тонет» в diminuendo. Хотя Шуман предписывает резкие акценты и сгеscendo, прерывающиеся внезапным ріапо.

Неосознание лейтинтонационности цикла отражается на его видении целого, так как в таком случае пьесы излишне отчленяются одна от другой, игнорируются шумановские указания attacca при переходах от одного интермеццо к другому, связующие нити между частями рвутся.

Определенную роль в скреплении пьес цикла «Интермеццо» выполняет интонация V - VI - V, появившаяся уже в начале основного раздела Allegro quasi maestoso № 1 (скачковый ход на нону, а возврат на секунду). 
В свободном варианте основного лейткомплекса (от т. 43): главенствует та же интонация cis-d-cis, что и в первой ячейке «мотто»; чуть позже в гаммообразном движении проходят и звуки a-gis второй ячейки вступления; от первоначального импульса заимствуется и пунктирный ритм.

И все же данная разновидность тематического ядра достаточно своеобразна и самостоятельна - прежде всего благодаря появлению более широкой мелодической линии и изменению ладового освещения: fis-moll вместо A-duг.

Родственно сумрачно-напряженным встревоженным образам «Крейслерианы» и начало № 1 «Интермеццо», хотя оно более угрюмо и зловеще. Д. Житомирский справедливо пишет об этой теме как о «родоначальнице целого большого круга шумановских образов, выражающих страстную и несколько сумрачную энергию» $[2,350]$.

Вероятно, творческим импульсом к созданию этих произведений были какие-то общие и очень близкие внутренние побудительные мотивы, что в итоге и обусловило их родство [5, 45]. Вспомним о тех возвышенных мечтах, которые владели Шуманом еще до написания цикла «Интермеццо» (обратим внимание на одну из дневниковых записей композитора 1831 года: «Я хочу измениться, я клянусь тебе в этом - дай мне только одного человека, одного-единственного, которому я могу отдать сердце - любимую, любимую, дай мне женское сердце - женское сердце!» (цит. по: [7, 45]). Вспомним также, что сочинение было первоначально посвящено тогда еще совсем юной Кларе Вик... [2, 351].

В нашем «Интермеццо» именно в начальной интонации VI-V ступеней концентрируется лирическая экспрессия пьесы. Нельзя не отметить, что в «книге невесты» (Brautbuch [8]), посвященной Кларе, есть набросок начала этого «Интермеццо», датированный октябрем 1839 года и представляющий собой гармонически и мелодически обогащенный вариант темы пьесы.

Относящееся к упомянутому наброску письмо содержит важное замечание: «То, что я написал выше, нечто вроде озарения. Гармония преследовала меня весь день» [8]. Х. Кёлер пишет по этому поводу: «Это можно понять как оглядку на лейпцигские времена 1832 года, время внутренней неуравновешенности, становления, когда рано охватившая его (Шумана. - Л. Д.) склонность к Кларе, тогда еще 13-летнему ребенку, казалась как бы освобождающим взглядом в далекую даль. В этом случае «Интер- 
меццо» воспринимаются как автопсихологически ориентированное произведение» [8].

Первое интермеццо и весь цикл находятся в определенном вариантно-вариационном соотношении и взаимосвязаны между собой лейтинтонациями, лейтмотивами, лейтгармонией, лейтритмом, лейттемами, лейтобразами.

Выводы. Жанровые открытия Роберта Шумана и особенности его мышления направлены далеко в будущее. Это относится и к жанру интермеццо, основоположником которого является Роберт Шуман, впервые создав произведение с таким названием. У него же интермеццо становится как самостоятельным произведением, так и частью цикла (фортепианного концерта). В дальнейшем жанр интермеццо стал чрезвычайно популярным, как самостоятельная пьеса и как часть циклического произведения: в сонатах, концертах, циклах различных пьес, куда вторгается и интермеццо.

У Шумана жанр интермеццо приобретает яркое внутреннее содержание, насыщенное серьезным драматургическим развитием, столь разнообразно используемым композитором. Шуман как бы зачал этот жанр и, вместе с тем, будто подвел итог развитию жанра в ранний период истории романтизма, показал его индивидуальные особенности и сосредоточенность на внутренней специфике содержательности и пианизма. Шуман совмещает классическое прошлое и современное, вобрав основы мышления романтизма и во многом предвосхитив будушее музыкального языка XX столетия. Интермеццо Шумана перспективно для исполнения как в Украине, так и в Китае.

\section{СПИСОК ЛИТЕРАТУРЫ}

1. Головинский Г. Роберт Шуман и русская музыка XIX века. Советская музыка. 1990. № 3. С. 46-54.

2. Житомирский Д. Роберт Шуман. Очерки жизни и творчества. М.: Музыка, 1964. 880 с.

3. Лу До. Лейтмотивизм цикла «Интермеццо» ор. 4 Роберта Шумана. Мyзичне мистецтво і культура: науковий вісник ОДМА імені А. В. Нежданової. Одеса: Друкарський дім, 2016. Вип. 23. С. 369-379.

4. Лу До Полісемія понять: інтермеццо, інтерлюдія, інтермедія. Міжкнародний вісник: Культурологія. Філософія. Музикознавство. К.: Міленіум, 2017. Вип. 1 (8). С. 206-211.

5. Меркулов А. Фортепианные сюитные циклы Шумана. Вопросы целостности композиции и интерпретации. М.: Музыка, 1991. 95 с. 
6. Мирошниченко С. Генезис жанра интермеццо. Годишньак учительчког факультета у Враньу. Вранье, 2015. С. 391-398.

7. Шуман Р. Письма (1817-1840) / пер. с нем. А. А. Штейнберг; ред. перевода и перевод части писем Н. А. Темчиной; сост., вст. статья, комм. Д. В. Житомирский. М.: Музыка, 1970. Т. 1.719 с.

8. Kohler H. Nachword in Schumenn R. Intermezzi op. 4 fur Klavier. Urtextausgabe. Lpz., 1977.

\section{REFERENCES}

1. Golovinskiy G. (1990) Robert Schumann and Russian music of the 19-th century. Sovetskaya muzyika, 3, P. 46-54 [in Russian].

2. Zhitomirskiy D. (1964) Robert Schumann. Essays on life and creativity. Moscow: Muzyika [in Russian].

3. Lu Do (2016) Leitmotivism of the cycle «Intermezzo» op. 4 Robert Schumann. Music art and culture, 23, Odessa: Drukarskiy dim, P. 369-379. [in Russian].

4. Lu Do (2017) To understand the whole: intertermezzo, internudiyya, intmededy. International Journal: Culturology. Philosophy. Musicology, 1 (8), Kyiv: Milenium, P. 206-211 [in Ukrainian].

5. Merkulov A. (1991) Syuitnye piano cycles of Schumann. Questions of integrity of composition and interpretation. Moscow: Muzyika [in Russian].

6. Miroshnichenko S. (2015) Genesis of intermezzo genre. Godishn'ak uchitel'chkog fakul'teta u Vran'u. Vran'ye [in Russian].

7. Shuman R. (1970) Letters (1817-1840). Vol. 1. (A. A. Steinberg, Trans. Ed. translation and translation of a part of letters by N. A. Temcina. Comp., intr. article, comm. D. V. Zhitomirsky). Moscow: Muzyika [in Russian].

8. Kohler H. (1977) Nachword in Schumenn R. Intermezzi op. 4 fur Klavier. Urtextausgabe. Leipzig [in German].

Стаття надійщла до редакції 29.11.2017 